Medical Science, Zanjan, Iran; ${ }^{2}$ slamic Azad University of Iran, Tabriz Branch, Medical Faculty, Tabriz, Iran; ${ }^{3}$ Urmia University of Medical Science, Urmia, Iran; ${ }^{4}$ Tabriz University of Medical Science, East Azerbaijan, Iran

Objective Comparison of active vs passive primary healthcare function in rural with urban setting at determine of delay to diagnosis and treatment of tuberculosis and its outcomes in West Azerbaijan province, Iran, at 2004-2009.

Material and Methods In this perspective study we used years TB new cases data that have been recorded by TB management center in West Azerbaijan province. Patient and health system delay were determined as number of days between onset of symptoms to diagnosis and diagnosis to start of treatment respectively.

Results At comparison of domicile, both of patient and health delay mean days were more in urban patients (respectively 241 vs 133, $p$ value $=0.02$ and 11 vs $7, p$ value $=0.006$ ). In rural patients, females at comparison of males had more mean total time delays (163 vs 115 , $\mathrm{p}$ value $=0.01$ ). Despite of higher mean of total delays in extra pulmonary to pulmonary at both of domicile (respectively urban 278 vs 232 and rural 197 vs 97), there was significantly difference in rural regions ( $p$ value $=0.0001$ ). Default rate in rural regions was less than urban settings (respectively $3.53 \%$ vs $6.08 \%$ ) and whereas success rate was more than it (respectively $81 \%$ vs $79 \%$ ).

Conclusion At regard to health system policy in Iran that primary healthcare for tuberculosis in rural regions is active whereas urban setting is passive, it seems there is urgent need to change of policy in case finding and case holding of patients in urban area to decrease time delays and increase positive outcomes.

\section{P1-198 STUDY OF SPATIAL DISTRIBUTIONS AND EFFECT OF THE PATIENT DISTANCE FROM HEALTH CENTER ON DEFAULT AND INTERRUPTED THERAPEUTIC OUTCOMES IN TUBERCULOSIS DISEASE USING GIS AND GPS, IN URMIA, IRAN, DURING 2004-2009}

doi:10.1136/jech.2011.142976d.91

${ }^{1} \mathrm{G}$ Kolifarhood, ${ }^{2} \mathrm{~S}$ Dastgiri, ${ }^{3,4} \mathrm{~S}$ Salarilak, ${ }^{1} \mathrm{~N}$ Khosravi, ${ }^{4} \mathrm{~A} N$ nejad, ${ }^{4} \mathrm{~B}$ Neamati, ${ }^{4} \mathrm{D}$ Khorasani, ${ }^{4} \mathrm{P}$ Mikaili, ${ }^{4} \mathrm{~A}$ Yousefzade, ${ }^{4} Y$ Mohammadpour, ${ }^{4} \mathrm{R}$ Ghareaghaji. ${ }^{1}$ Zanjan University of Medical Science, Zanjan, Iran; ${ }^{2}$ Tabriz University of Medical Science, East Azerbaijan, Iran; ${ }^{3}$ Islamic Azad University of Iran, Tabriz Branch, Medical Faculty, Tabriz, Iran; ${ }^{4}$ Urmia University of Medical Science, West Azerbaijan, Iran

Objective To determine of the spatial distributions of tuberculosis (TB) and effect of patient distance from the health center on default or interrupted therapeutic outcomes in Urmia, Iran, during 2004-2009.

Material and Methods In this cross sectional study we used the data of 452 new TB cases, which have been recorded by TB management center in Urmia, capital of West Azerbaijan province, during a fiveyear period. In order to identifying the significant geographical clusters, we used the "Average Nearest Neighbour" method. Linear regression method was used to determine linear correlation between patients distance and number of default and interrupted therapeutic outcomes.

Results Five countryside areas had significantly spatial clusters of TB $(p<0.0001)$. As the distance of patient from TB health center are increased, the number of the default and interrupted cases were also increased $\left(r^{2}=0.25, p=0.04\right)$. In comparison with the number of default and interrupted cases and the mean distances of TB health center, wherever mean distance was more than $1 \mathrm{Km}$, number of default and interrupted cases were more than $3(p=0.02)$.

Conclusion Spatial distributions of tuberculosis disease in Urmia are not randomly and suburban areas need more serious attentions by policy makers and health planners. According to the health system in Iran, health posts has not actively role in treatment of TB patients at urban settings. As a result, if the health posts are contributed to in the $\mathrm{TB}$ treatment programs, the patient distance from the treating health centers will decreased and subsequently the positive therapeutic outcomes will grow.

\section{P1-199 LIMITATIONS OF THE "HIGH-RISK STRATEGY" FOR LONG-TERM DISABILITY CARE PREVENTION: REVISITING GEOFFREY ROSE}

doi:10.1136/jech.2011.142976d.92

${ }^{1} \mathrm{~K}$ Kondo, ${ }^{*}{ }^{1} \mathrm{H}$ Hirai, ${ }^{2} \mathrm{~T}$ Ojima, ${ }^{3} \mathrm{I}$ Kawachi. ${ }^{1}$ Nihon Fukushi University, Nagoya, Aichi, Japan; ${ }^{2}$ Hamamatsu University School of Medicine, Hamamatsu, Shizuoka, Japan; ${ }^{3}$ Harvard School of Public Health, Boston, Massachusetts, USA

Introduction In 2006, the Japanese government introduced a new prevention policy to limit the growth of old age disability care. The policy is based on what Geoffrey Rose called the "high-risk strategy" of prevention, and seeks to identify individuals with multiple risk factors. We provide cohort data to examine the feasibility of the policy. Methods Older people ( $\geq 65$ years old, $n=11889$ ) who were independent in activities of daily living were followed up for 3 years as a part of AGES (Aichi Gerontological Evaluation Study) project. The endpoint is becoming functionally dependent. We used eligibility criteria for public long-term care insurance policy.

Results At baseline, $63 \%$ of subjects had no risk factors and 3\% had three or more risk factors (high-risk group, HRG). After 3 years, 1149 individuals become dependent. Among the HRG, 32\% lost independence compared to $6 \%$ of those with no risks. Although the HRG showed a higher rate of functional decline, they only comprised $9 \%$ of those who became dependent. If the targeted population is expanded to those with one or more risk factors, $57 \%$ of dependent people become eligible but the number requiring surveillance rises to more than ten million individuals in the country, with substantial costs of screening.

Conclusion The majority of cases of disability arises among individuals with fewer risk factors, illustrating Rose's principle of the prevention paradox. Pursuing the high-risk strategy results in lower coverage, as well as substantial costs of screening. This suggests that a population strategy is the only sustainable approach.

\section{P1-200 PROPORTION WITH CHILDREN UNDER 2 YEARS IN BRAZIL WHO HAD AN AVOIDABLE HOSPITALISATION, 2006}

doi:10.1136/jech.2011.142976d.93

1,2T Konstantyner, ${ }^{*}{ }^{1} \mathrm{~J}$ A Taddei, ${ }^{2} \mathrm{~L}$ Rodrigues. ${ }^{1}$ Universidade Federal de São Paulo, São Paulo, São Paulo, Brazil; 'London School of Hygiene \& Tropical Medicine, London, UK

Introduction Prevention of hospitalisation is a public health challenge worldwide. Many of the reasons for hospitalisation in developing countries should be avoided by presence of effective health systems. The aim of the study was to identify the proportion of young children with history of avoidable hospitalisation in the previous 12 months in Brazil, in order to gain insight into distribution and causes of hospitalisation to inform policies to prevent children hospitalisation.

Methods Analysis of causes of avoidable hospitalisation among children under 2 years of age based on data from the Brazilian DHS 2006 conducted by the Ministry of Health. The data collection was carried out in households with children by means of interviews with their mothers or guardians.

Results Mothers or guardians of 1901 children were examined. $11.8 \%$ reported infants to have been hospitalised at least once in the previous 12 months. The proportion with at least one hospitalisation in the previous year were $2.0 \%$ from pneumonia, $3.2 \%$ from bronchitis, $2.6 \%$ from diarrhoea, $0.5 \%$ from accident and $3.6 \%$ from others causes. 
Conclusion Respiratory and gastrointestinal diseases and accidents were predominant causes of hospitalisation of children under 2 years of age. The results demonstrate that prevention activities could be essential strategies in order to reduce proportions of hospitalisation among children under 2 years of age in Brazil at least by half. Besides, this study suggests that such investment in health promotion could improve the health profiles of children in developing countries.

\section{P1-201 USING EPIDEMIOLOGY DATA FOR EVALUATING OF ECONOMIC BURDEN OF CARDIOVASCULAR DISEASES IN RUSSIAN FEDERATION}

doi:10.1136/jech.2011.142976d.94

\author{
A Kontsevaya, ${ }^{*}$ A Kalinina, I Koltunov. National research center for preventive \\ medicine, Moscow, Russia
}

Purpose To study the economic burden of cardiovascular diseases (CVD) in Russian Federation in 2006-2009.

Methods The economic burden was calculated by the cost of illness method. The calculations included direct costs of healthcare system and indirect costs, associated with premature death in working age and disability. We used official statistics of healthcare resources utilisation, associated with CVD, the results of epidemiological surveys of CVD, mortality statistics in Russia in 2006-2009.

Results The total economic burden of CVD increased from 20.6 billions of euro in 2006 till 26.6 billion of euro in 2009 what was equal to $3.1 \%-2.8 \%$ of GDP of Russian Federation. The increasing of the burden was mainly caused by the price increasing and in some degree by the increasing of PCI in CHD patients in recent years. Direct costs accounted $21.3 \%$ of total cost of CVD (5.7 billions of euro), indirect costs-78.7\% (20.9 billions of euro) in 2009. Indirect costs mainly consisted of the GDP losses because of premature death of working age men. CHD represented $37.8 \%$ and cerebrovascular diseases $17.1 \%$ of overall CVD costs. In-hospital care represented $47.5 \%$ of direct costs, out hospital visits-21.8\%, medication $-20.7 \%, \mathrm{PCI}-4.1 \%$ and emergency care $4.1 \%$ of direct costs in 2009 , respectively. CHD represented $45.3 \%$ of direct cost, because of large duration of hospitalisation and PCI costs.

Conclusion CVD is a big public health challenge in Russia. The results of economic burden assessment should help policy makers evaluate policy impact and prioritise expenditures.

\section{P1-202 MONITORING OF SOCIO-DEMOGRAPHIC DIFFERENCES IN HEALTH BEHAVIOURS IN LITHUANIA}

doi:10.1136/jech.2011.142976d.95

V Kriaucioniene, ${ }^{*}$ J Klumbiene, J Petkeviciene. Institute for Biomedical Research, Medical Academy, Lithuanian University of Health Sciences, Kaunas, Lithuania

Introduction Monitoring of heath behaviour on a national level is an important vehicle for health promotion and disease prevention, planning and evaluation. The aim of the study was to analyse the time trends of socio-demographic differences in behaviours of population.

Methods From 1994 to 2010 nine health behaviour surveys have been carried out in Lithuania. For every survey random sample of 3000 Lithuanians aged 20-64 was taken from the National Population Register. The response rates varied from $54 \%$ to $74 \%$. The study material was collected by mailed questionnaires covering socio-demographic characteristics and health behaviours factors.

Results Over the last 16 years the prevalence of daily smoking has decreased significantly among men (from $43.8 \%$ in 1994 to $34.2 \%$ in 2010 ) but it increased among women (from $6.8 \%$ to $15 \%$ respectively). Daily smoking and passive smoking at work has remained more prevalent among less educated persons than among highly educated persons. Bear consumption increased in both genders in all educational groups. The frequency of strong alcohol drinking rose among women in all educational groups, while among men it remained stable. Since 1994 nutrition habits have changed in the direction of more healthy diet in all educational groups. Daily consumption of fresh vegetables increased from $4.5 \%$ in 1994 to $20.4 \%$ in 2010. Educational inequalities in nutrition habits have diminished, but some differences have still remained significant.

Conclusions The established sociodemographic differences in health behaviour should be taken into account in elaboration of more effective health promotion programmers in Lithuania.

\section{P1-203 SOCIAL AND GENDER DIFFERENTIALS IN CHILDHOOD MORTALITY IN RURAL NORTH INDIA}

doi:10.1136/jech.2011.142976d.96

\begin{abstract}
${ }^{1,2} \mathrm{~A}$ Krishnan, ${ }^{*} \mathrm{P}$ Dwivedi, ${ }^{1} \mathrm{~V}$ Gupta, ${ }^{1} \mathrm{C}$ Pandav, ${ }^{2} \mathrm{~N}$ Ng, ${ }^{2} \mathrm{P}$ Byass. ${ }^{1} \mathrm{All}$ India Institute of Medical Sciences, New Delhi, India; ${ }^{2}$ Umeå Centre for Global Health Research, Umea, Sweden
\end{abstract}

Introduction Achieving Millennium Development Goals on childhood mortality in developing countries requires that inequities be addressed. This study examined changing gender differentials as social and economic improvement occurred in a rural north Indian community.

Methods A dynamic cohort of children aged $<5$ years old in 10 villages under Ballabgarh HDSS were followed from $1^{\text {st }}$ January 2008 to death, age 5 or data censoring on $31^{\text {st }}$ December 2010. Data on births, mortality, caste and parental literacy are routinely collected and stored in electronic databases to which information on wealth Index was appended in 2010. Cox proportional hazards modelling was used to produce HRs for mortality in girls according to socioeconomic strata after adjustment for birth order, number of siblings and other socioeconomic variables.

Results The mortality rate for the cohort was 67.9 per 1000 live births $(B=74.4 ; G=62.4)$. This declined significantly as wealth index improved (from 102.4 to 25.4 per 1000 live births). The HR for girls declined from 1.57 (95\% CI 1.0 to 2.5) in the wealthiest to 0.67 (0.3 to 1.4 ) in the lowest tertile. There was no change in total or sex specific mortality rates according to caste or father's education. Mothers' education beyond $10^{\text {th }}$ grade resulted in sharp decline in mortality (14 per 1000 live births) but did not impact the sex differential in mortality. The sex ratio at birth was worst for population with highest wealth index and highest level of maternal educational attainment.

Conclusion Major social and gender differentials persisted in this study population with gender discrimination moving from after to before birth.

\section{P1-204 EPIDEMIOLOGY OF DISABILITY IN INDIA: OBSERVATIONS FROM A RECENT STUDY IN TWO STATES, 2009-2010}

doi:10.1136/jech.2011.142976d.97

A Kumar, ${ }^{*}$ S Husain. National JALMA Institute for Leprosy \& Other Mycobacterial Diseases (ICMR), Taj Ganj, Agra, Uttar Pradesh, India

Introduction Disability refers to functional impairment of any part of the body and may be congenital or acquired. Estimation of disability load and its causes is an important index for determining services for social justice and rehabilitation. This study aimed to estimate the community disability burden in India at the request of the Government of India and WHO. 